\title{
Hedge Fund Seeding with Fees-for-Guarantee Swaps
}

\author{
Yun Feng $^{\mathrm{a}}$, Binghua Huang ${ }^{\mathrm{a}}$ and Hai Zhang ${ }^{\mathrm{b}}$ \\ ${ }^{a}$ Antai College of Economics \& Management, Shanghai Jiao Tong University, Shanghai, \\ P.R.China; ${ }^{b}$ Department of Accounting \& Finance, Strathclyde Business School, UK
}

\author{
ARTICLE HISTORY \\ Compiled March 19, 2018
}

\begin{abstract}
This article introduces a new instrument in the context of hedge fund seeding, which we call fees-for-guarantee swap, with the aim of alleviating the early-stage funds (ESF) managers' financial constraint caused by severe asymmetric information between investors and managers. The swap plays a role in enhancing the ESFs manager's credibility by swapping part of her fees for an insurance on the behalf of seeding investors, whom would be fully refunded once the fund defaults. We set up a dynamic continuous-time framework within which closed-form prices for seed capital, guarantee costs and other claims have been derived. Our numerical findings indicate that incentive compensations, managerial ownership and hedge funds liquidation risks not only inhibit ESFs managers' risk-shifting incentive but align interests among ESFs manager, seeder and insurer as well.
\end{abstract}

\section{KEYWORDS}

Hedge fund seeding; Fees-for-seed swap; Fees-for-guarantee swap; Risk-shifting

\section{Introduction}

Over the past few years, there has been a significant increase in both the number of hedge fund seeders and the amount of capital available for hedge fund seeding. According to HFM-Week research, in November 2011, seeders had approximately $\$ 4.6$ billion in available capital, compared to approximately $\$ 1$ billion just one year earlier.

Despite the recent growth in available seed capital, there still remains a tremendous shortage of capital for the early-stage funds (ESFs, henceforth). This is because most capital allocators increasingly focus on larger established hedge funds considered highly credible, on one hand, and a larger talent pool of ESFs managers is now competing for the available seed capital, on the other hand. Moreover, barriers to entry for ESFs are much steeper today than that before the 2008's financial crisis. ${ }^{1}$ Thus financial constraint faced by ESFs managers nowadays is much more serious than before.

Normally in a hedge fund seeding business deal, a seed investor or seeder commits to providing a remarkable amount of capital as an "anchor investor" in a new fund in

\footnotetext{
CONTACT Hai Zhang. Email: hai.zhang@strath.ac.uk

${ }^{1}$ Title IV of the Dodd-Frank Wall Street Reform and Consumer Protection Act compels the U.S. Securities and Exchange Commission (SEC) to impose reporting requirements on all hedge funds as it deems necessary or appropriate in the public interest or for the assessment of systemic risk. The article, "Launch bad; Hedge funds", published in The Economist 20 Apr. 2013: 79 (US) states that it is much harder to break into the hedge-fund world than before, because of the rising expenses, more risk-averse investors and enhanced regulation.
} 
exchange for a share of "enhanced economics" which is usually the fees that the ESFs manager generates from the entire pool of assets in the fund. ${ }^{2}$ A widely accepted rule of thumb is for a seeder to expect $1 \%$ of revenues for each $\$ 1$ million of seed capital provided for seed transactions no larger than $\$ 50$ million. However, it would not be surprising to see a $25 \%$ revenue share on a seed investment of US $\$ 100$ million as seed arrangements can vary substantially based on factors such as managerial experience or alpha strategy, the amount of seed capital provided, and relative negotiating power of each party. If fees-for-seed swap has been structured properly, the seeding vehicle could be highly beneficial to both ESFs managers and seeders. ${ }^{3}$

Although fees-for-seed swaps in reality has, to some extent, solved ESFs managers' financial constraint, there still remains a huge gap between the highly demanded seeding capital and the limited supply at the hedge fund seeding stage. And the borne severe information asymmetry between seeders and ESFs managers has always been the key factor holding back the development of hedge fund seeding business, especially in the aftermath of 2008 financial crisis. Therefore, an insurer has been firstly introduced in our paper with the aim to improve ESFs managers credibility and thus solve the problem of information asymmetry between seeders and ESFs managers.

Similar to Tang and Yang (2017), we focus only the information asymmetry between seeders and ESFs managers, and simply assume no such information asymmetry between ESFs managers and insurers. This assumption is based on the following reasons: First, insurers might act as hedge funds long-term strategic partners, thus have more insider knowledges than seeders; Second, insurers are more professional in terms of monitoring risks, thus know well of ESFs managers' credit level or default risks.

Inspired by SMEs' experience of overcoming borrowing constraints in China as discussed in Yang and Zhang (2013) and Tang and Yang (2017) among others, financial constraint results from information asymmetry faced by ESFs managers could be largely alleviated by introducing the fees-for-guarantee swap supported by a commercial guarantee-company or an insurer. Unlike the traditional credit scheme, ESFs managers in our innovative setting pay guarantee company or insurer a certain portion of her fees, as guarantee costs instead of regular fees. Once the hedge fund is liquidated either exogenously by a crisis shock or endogenously by investors, the seeder will receive compensatory payment from the insurer. Indeed the seeder participated in the fees-for-guarantee swap obtains portfolio insurance, thus her return distribution has been altered such that her downside risks is well controlled while allowing participation of upside potential gains.

Nevertheless a rule of thumb in designing seed arrangements and a few simple models featuring hedge fund seeding return have been proof popular in practice, the theoretical research on the contract costs and optimal designing of these contracts is quite limited. ${ }^{4}$ Under the Black-Scholes framework, we have derived closed-form solutions for seed costs and guarantee costs as well. Moreover, we develop a numerical

\footnotetext{
${ }^{2}$ Hedge fund managers normally receive $20 \%$ of the increase in fund value in excess of the last recorded maximum, i.e. high-water-mark ( HWM, henceforth) as incentive fees in addition to $2 \%$ of the asset under management (AUM) as management fees, which "two-twenty" viewed as the industry's norm. Several academic articles study the characteristics of hedge fund fees, such as Fung and Hsieh (1997), Fung and Hsieh (1999)), and Aragon and Nanda (2012), as well as several articles in the Wall Street Journal.

${ }^{3}$ Based on the Consumption-CAPM framework, Ewald and Zhang (2016) provides strong evidences for the benefits of fees-for-seed swaps.

${ }^{4}$ For example, Larch Lane Advisors (LLC) has constructed a simple model to project returns and cash flows for a seeded fund, featuring the innovative seeding strategy. Ewald and Zhang (2016) provide first theoretical research for these problems under the seeding stage, but they only consider the fees-for-seed swap without insurance.
} 
procedure to analyse impact of managerial ownership, fund liquidation on the risk shifting behaviour of ESFs managers with a convex payoff compensation structure.

This paper is closely related to Goetzmann, Ingersoll and Ross (2003), which provides the first quantitative intertemporal valuation framework of investors' payoff and managers' fees in a setting where the fund's value follows a log-normal process and the fund managers have no discretion over the choice of portfolio. However, our paper mainly focuses on the innovation of hedge fund seeding business like fees-for-seed and fees-for-guarantee swaps. Moreover, we provide a dynamic framework for valuing the costs of these swaps, as well as modelling the impact of HWM, managerial ownership and fund liquidation on ESFs managers' risk shifting behaviour, at the hedge fund seeding stage.

An companion paper by Ewald and Zhang (2016) has done a similar research on the hedge fund seeding businesses. With a strong focus on the effect of frictions of incomplete markets, such as idiosyncratic risks, Ewald and Zhang (2016) provides a dynamic valuation model of the hedge fund seeding business, by solving the consumption and portfolio-choice problem for a risk-averse manager, who launches a hedge fund via a seeding vehicle. Unlike Ewald and Zhang (2016) which spotlights the idiosyncratic risks of seeding business, we focus on the borne information asymmetry between seeders and ESFs managers. A new financial contract, we refer to fees-for-guarantee swap, has been introduced in our paper with the aim of solving this problem. Another dramatic difference between Ewald and Zhang (2016) and our paper is the risk profiles regarding to seeders' investment. Thanks to the fees-for-guarantee swap, the seeder's investment downside risks in our paper has been well under control when the fund defaults, whereas in Ewald and Zhang (2016) the seeder could lost every penny invested in the fund. Finally, both papers show that ordinary investors are more willing to invest in an ESFs backed up by seeders with innovative contracts. However, the mechanisms under are quite different: Ewald and Zhang (2016) argue that ordinary investors get incentives and benefit from their senior positions at the "waterfall" structure, while here in our framework interests between ordinary investors and the ESFs manager are well aligned as the manager has skin in the game.

Yang and Zhang (2013) provide a formal study on equity-for-guarantee swap on SMEs' financing problems, which share some similarities for those of ESFs managers. Following this, the financial constraint faced by ESFs managers could be largely solved by introducing fees-for-guarantee swaps in hedge funds. Moreover, our model focuses on the impacts of fees-for-guarantee swaps on ESFs manager's risk shifting behaviour and highlights hedge fund risk management at the hedge fund seeding stage.

This current paper also relates to some general portfolio insurance literature. Along the lines of Leland and Rubinstein (1976) and Basak (2002)amongst other studies, Ho et al. (2010) provide a general review of of portfolio insurance strategies, claiming that portfolio insurance is a dynamic hedging process that allows market participants to alter the return distribution such that the downside risk is well controlled while allowing participation on the upside gains. The seeder's return distribution in our framework indeed has been changed due to the fees-for-guarantee swap. Unlike specific popular PI methods in practice, e.g. Option Based Portfolio Insurance (OBPI) that is firstly introduced by Leland and Rubinstein (1976), and Constant Proportion Portfolio Insurance (CPPI) by Black and Jones (1987) among others, the PI obtained by the seeder here is provided by a third party, an insurance company, other than the dynamic hedging by the seeder herself. Another interesting feature in our model is that portfolio insurance will be terminated at random liquidation point. As the seeder only seeks to insure the fund's default risk. Moreover, what we are mostly interested in this current 
paper is the outcome profile of portfolio insurance provided by the insurer, not specific PI strategies that might be adopted by the insurer for risk hedging purpose.

Our article is closely related to the substantial literature that examine the effects of convex payoff compensation on the risk choices of hedge fund managers. ${ }^{5}$ Carpenter (2000) asserts that it is optimal for hedge fund managers, who faces no explicit downside risk, to choose infinite volatility as asset value goes to zero. On the contrary, managers should reduce the volatility to ensure that liquidation does not occur. Similarly, Basak, Pavlova, and Shapiro (2007) and Aragon and Nanda (2012) argue that the convex payoff structure of a manager does not necessarily induce risk shifting when fund undertakes poor performance, as long as she is exposed to downside risk, either through her ownership of fund share or her management fees. Aragon and Nanda (2012) empirically analyse the relationship between risk shifting by a hedge fund manager and the manager's incentive contract, personal capital stake, and the risk of fund closure. Other related empirical research include the work of Agarwal, Daniel and Naik (2009) and Agarwal, Daniel and Naik (2011). We are unaware, however, of any existing model that both captures the managerial skill (alpha) and the convex compensation at the hedge fund seeding business. Capturing these institutional features in a model that is sufficiently tractable to evaluate the costs of these innovative swaps in the hedge fund seeding business is a main contribution of this study.

The rest of the paper is structured as follows. In section 2, we develop two models of hedge fund seeding innovations and analyse the impact of incentive contracts, managerial stake, and hedge fund liquidation on managers' risk shifting behaviour. Illusive numerical results of our theoretical model are provided in section 3 to shed more insights of the hedge fund seeding business. Finally, section 4 concludes. The appendix collects the equilibrium prices of contingent claims, such as management and incentive fees as well as investors' payoff.

\section{Modeling hedge fund seeding innovation}

In this section, we first present a benchmark model discussing hedge funds dynamics with fees-for-seed swap only. A dynamic framework of hedge fund seeding has been set up latter, including both fees-for-seed swaps and fees-for-guarantee swaps. Lastly, we look into the breakeven alpha strategy, and we show that, with the help of it, ordinary investors are more willing to invest in a ESFs backed up by seeding investments.

\subsection{Hedge fund dynamics and valuation}

\subsubsection{Dynamics of the asset under management}

We assume the cumulative-return process $R$ of the diversified market portfolio satisfies

$$
d R_{t}=\mu_{M} d t+\sigma_{M} d B_{t}, \quad t \geq 0
$$

where $\mu_{M}$ and $\sigma_{M}>0$ are constants. We denote by $S$ the value process of the asset under management (AUM, henceforth) and by $H$ the current HWM, which is the highest level that the AUM has reached subject to certain adjustments. We assume

\footnotetext{
${ }^{5}$ See, for example, Ross (2004), Panageas and Westerfield (2009) Hodder and Jackwerth (2007) and Lan,
} Wang and Yang (2013) among others. 
for $t \geq 0$ that

$$
\frac{d S_{t}}{S_{t}}=(\mu-\delta-c) d t+\rho \sigma d B_{t}+\sqrt{1-\rho^{2}} \sigma d Z_{t}, \quad S_{0} \text { given, } \quad S_{t}<H_{t},
$$

where $\delta$ is the regular withdrawal rate, $c$ is the management fee rate, and $\rho \in[-1,1]$ is the correlation coefficient between the hedge fund and the market.

\subsubsection{Management compensation contracts}

In hedge funds industry, ESFs managers are commonly compensated via both management fees which is specified as a constant fraction $c$ of AUM and incentive fees accompanied by a HWM provision. The HWM process, denoted by $H$, evolves deterministically if it is higher than AUM according to

$$
d H_{t}=\left(g-\delta-c^{\prime}\right) H_{t} d t
$$

where $g$ is the rate of interest or an other contractually stated rate and $c^{\prime}$ is the cost or fees allocated to its reduction. If AUM reaches a new high, the HWM is reset to this higher level.

\subsubsection{Hedge fund liquidation}

Following Goetzmann, Ingersoll and Ross (2003), the fund will be liquidated with an exogenously given probability $\lambda$ per unit of time. Such liquidation time is donated by $\tau_{1}$. In addition, an endogenous liquidation required by ordinary investors may occur if the fund performance is sufficiently poor. Similar to Grossman and Zhou (1993) and Lan, Wang and Yang (2013) among others, who assume the liquidation threshold is $l H_{t}$, ours is a lower value of $b \equiv l(1-\phi) H_{t}$, where $\phi$ is the fraction of AUM owned by the managers. This is because ESFs managers owns $\phi$ portion of the fund while the outside investors have the remains, thus the liquidation barrier triggered by outside investors would be $\phi$ percent lower in our setting. The hitting time of the endogenous liquidation threshold is denoted by $\tau_{2}$. Therefore, we can define the liquidation time as $\tau \equiv \min \left\{\tau_{1}, \tau_{2}\right\}$

Unlike the existing literature, our model assumes a lower liquidation boundary, due to the managers' ownership of AUM under the arrangement of the innovative contract. In view of this, the new financing scheme of hedge fund generates more profits and leads to a significant welfare improvement. ${ }^{6}$

\subsubsection{The pricing of fees and investors' claim}

We first denote by $\eta \equiv\left(\mu_{M}-r\right) / \sigma_{M}$ the Sharpe ratio of the market. Following Goetzmann, Ingersoll and Ross (2003), we define $\alpha \equiv \mu-r-\beta\left(\mu_{M}-r\right) \equiv \mu-r-\rho \sigma \eta$

\footnotetext{
${ }^{6} \mathrm{~A}$ number of independent studies have concluded that on average, ESFs outperform more established funds as being either smaller and nimbler, or hungrier for returns. Hedge Fund Research (HFR) found that over the 10-year period from 1994 to 2004, funds with less than a three-year track record outperformed older funds by over $5 \%$ annually, with nearly identical volatility. Similarly, a 2009 study by PerTrac Financial Solutions finds that younger and smaller funds have outperformed larger and older funds, over the long term. Other studies, Aiken, Clifford and Ellis (2013) and Aggarwal and Jorion (2010) made a number of adjustments to raw performance data, to mitigate survivorship or backfill biases. Aggarwal and Jorion (2010) reached the conclusion that managers generate abnormal (excess) performance of $2.3 \%$ during their first two years relative to later years.
} 
as the premium return of ESFs, which is considered as an excess return generated by managerial skills. The risk-adjusted expected growth of the hedge fund under $\mathbb{Q}$ is then given by $\nu \equiv \mu-\rho \sigma \eta=\alpha+r$. Accordingly, the net asset value of the hedge fund follows

$$
\frac{d S_{t}}{S_{t}}=(\alpha+r-\delta-c) d t+\rho \sigma d B_{t}^{\mathbb{Q}}+\epsilon d Z_{t}, S_{t}<H_{t},
$$

where $Z$ and $B^{\mathbb{Q}}$ defined by $B_{t}^{\mathbb{Q}} \equiv B_{t}+\eta t$ are $\mathbb{Q}$-Brownian motion. Therefore, at any current time $t \geq 0$, according to (4), we get the present values of annual fee, the performance fee and the investors' claim respectively as follows:

$$
\begin{gathered}
A\left(S_{t}, H_{t}\right)=\mathbb{E}_{t}^{\mathbb{Q}}\left[\int_{t}^{\tau} e^{-r(s-t)} c S_{s} d s\right], \\
P\left(S_{t}, H_{t}\right)=\mathbb{E}_{t}^{\mathbb{Q}}\left\{\int_{t}^{\tau} e^{-r(s-t)} k\left[d H_{s}-\left(g-\delta-c^{\prime}\right) H_{s} d s\right]\right\}, \\
I\left(S_{t}, H_{t}\right)=\mathbb{E}_{t}^{\mathbb{Q}}\left[\int_{t}^{\tau} e^{-r(s-t)} \delta S d s+e^{-r(\tau-t)} S_{\tau}\right] .
\end{gathered}
$$

Thus, the value of the total management fees is given by

$$
F\left(S_{t}, H_{t}\right) \equiv A\left(S_{t}, H_{t}\right)+P\left(S_{t}, H_{t}\right) .
$$

The value of all these contingent claims could be explicitly derived, please refer to the Appendix A for computation details.

\subsection{A benchmark model of hedge fund seeding innovation}

In order to reach the initial AUM target and cover organizational expenses, ESFs managers usually seek help from seeders by swapping part of their fees for seed capital. Under the arrangement of the fees-for-seed swap, the ESFs manager receives the amount $\phi S_{0}$ of seed capital at the cost of $\psi$ of her total fees. Thus, the manager's total compensation denoted by $\underline{M V}\left(S_{t}, H_{t}\right)$ is given by

$$
\underline{M V}\left(S_{t}, H_{t}\right)=(1-\psi) F\left(S_{t}, H_{t}\right)+\phi I\left(S_{t}, H_{t}\right),
$$

where the total fees $F\left(S_{t}, H_{t}\right)$ and the investor payoff $I\left(S_{t}, H_{t}\right)$ are defined in Equations (A.11) and (A.13) respectively.

Similar to Ewald and Zhang (2016) that the seed capital provided by the seeder must be equal to equilibrium value of the fees allocated to the seeder, thus the swap ratio, denoted by $\psi$, is determined by

$$
\psi F\left(S_{0}, S_{0}\right)=\phi S_{0},
$$


where the annual fee $F\left(S_{0}, S_{0}\right)$ is defined in Equation (A.11) ${ }^{7}$. After rearranging the above equation, the fraction $\psi$, referred to as seed cost in the following text, is given by

$$
\psi=\frac{\phi(\chi+c)\left\{\theta_{2}(1+k)-1-b^{\bar{\theta}}\left[\theta_{1}(1+k)-1\right]\right\}}{c\left\{\theta_{2}(1+k)-1-b^{\bar{\theta}}\left[\theta_{1}(1+k)-1\right]\right\}+\left(1-b^{\bar{\theta}}\right) \chi k+\bar{\theta}(1+k) c b^{1-\theta_{1}}},
$$

where $\bar{\theta} \equiv \theta_{2}-\theta_{1}$, and $\chi \equiv \delta+\lambda-\alpha, \theta_{1}$ and $\theta_{2}$ are respectively the smaller and larger roots of a characteristic quadratic equation defined in Appendix A.

The seed cost in practice is determined via the rule of thumb; however, it is endogenously derived in our model. Interestingly, the relationship between fees-for-seed ratio and seed capital is linear when there is no exogenous liquidation risk $(l=0)^{8}$, which is quite similar to the rule of thumb. Clearly, the realistic value $\underline{S V}\left(S_{t}, H_{t}\right)$ of the seeder's claim is given by

$$
\underline{S V}\left(S_{t}, H_{t}\right)=\psi F\left(S_{t}, H_{t}\right) .
$$

Finally, the total present value of hedge fund $\underline{H F V}\left(S_{t}, H_{t}\right)$ is the sum of the managerial compensation, the seeder's and ordinary investors' claim, i.e.

$$
\begin{aligned}
\underline{H F V}\left(S_{t}, H_{t}\right) & \equiv \underline{M V}\left(S_{t}, H_{t}\right)+\underline{S V}\left(S_{t}, H_{t}\right)+(1-\phi) I\left(S_{t}, H_{t}\right), \\
& =\underline{F}\left(S_{t}, H_{t}\right)+I\left(S_{t}, H_{t}\right)
\end{aligned}
$$

which is similar to Goetzmann, Ingersoll and Ross (2003) but has a quite different asset structure.

\subsection{Hedge fund seeding innovation with both fees-for-seed swap and fees-for-guarantee swap}

To alleviate financial constraint of ESFs managers, hereafter we introduce a feesfor-guarantee swap in our model, which specifies that the ESFs manager gives up the fraction $\varphi$ of her fees to get the seeder's payoff insured. Once the hedge fund liquidates, an insurer, instead of the manager, must pay the amount $\phi S_{0}$ of cash to the seeder. As a return for the guarantee, the insurer gets a fraction, denoted by $\varphi$, of the manager's fees. ${ }^{9}$

Obviously, seeders are exposed to limited risks due to the fees-for-guarantee swap. Therefore seeders have stronger incentives to invest in the fund. Manager's compensation under the innovative guarantee scheme, i.e. $M V\left(S_{t}, H_{t}\right)$, is

$$
\begin{aligned}
M V\left(S_{t}, H_{t}\right) & =(1-\bar{\psi}-\varphi) F\left(S_{t}, H_{t}\right)+\phi I\left(S_{t}, H_{t}\right), \\
& =(1-\bar{\psi}-\varphi-\phi) F\left(S_{t}, H_{t}\right)+\phi H F V\left(S_{t}, H_{t}\right),
\end{aligned}
$$

\footnotetext{
${ }^{7}$ Unlike the fees structure $G$ in Ewald and Zhang (2016), the fees $F$ in our model is the same part $F$ as in Equation (20 in Ewald and Zhang (2016) or Equation (11a) in Goetzmann, Ingersoll and Ross (2003). As Ewald and Zhang (2016) focus on the lock-up period of seeding businesses, their fees structure $G$ in Equation (18) includes both the management fees and performances during the lock-up period and afterwards, thus the seed costs ratio can be calculated numerically instead of a close-formed solution. While here we place our emphasis on fees-for-guarantee swaps and consider only the afterwards with on idiosyncratic risks Goetzmann, Ingersoll and Ross (2003).

${ }^{8}$ One can obtain the results easily by substituting $l=0$ into Equation (11).

${ }^{9}$ Unlike the normal credit scheme, however, the hedge fund manager in the new credit guarantee scheme must pay to the guarantee company a portion $(\varphi)$ of her fees(including both management fees and incentive fees) as guarantee costs instead of the regular guarantee fees.
} 
where $H F V\left(S_{t}, H_{t}\right)$ is the total fund's value.In the above equation, we notice that the manager gives up $\varphi F\left(S_{t}, H_{t}\right)$ to an insurer in the new setting. Naturally, the value $G V\left(S_{t}, H_{t}\right)$ of the insurer's claim is

$$
G V\left(S_{t}, H_{t}\right)=\varphi F\left(S_{t}, H_{t}\right) .
$$

In general, an insurer will diversify her risk by signing many contracts with different hedge funds. Thus, the idiosyncratic risk of a hedge fund taken on by the insurer will be well-diversified and the present value of insurer's compensatory payment $V_{\text {guar }}$ should equal the market value of fees allocated to the insurer when the swap is signed, i.e.

$$
V_{\text {guar }} \equiv G V\left(S_{0}, S_{0}\right)
$$

At fund liquidation, the seeder claims her initial seed capital $\phi S_{0}$ from the insurer. In equilibrium, the insurer's payoff from the swap should equal to her guarantee liability, which is

$$
V_{\text {guar }} \equiv p_{b}\left(b, s_{0}\right) \phi S_{0},
$$

where $p_{b}\left(b, s_{0}\right)$, the market value of a security that claims one unit of account at the hitting time $\tau(b)=\inf \left\{t \geq 0: s_{t} \leq b\right\}$, is given by ${ }^{10}$

$$
p_{b}\left(b, s_{0}\right)=\left(\frac{s_{0}}{b}\right)^{\theta_{1}} .
$$

Now we can easily compute the guarantee cost, $\varphi$, by submitting Equations (16) and (17) into Equation (15):

$$
\varphi=\frac{p_{b}\left(b, s_{0}\right) \phi S_{0}}{F\left(S_{0}, S_{0}\right)}=p_{b}\left(b, s_{0}\right) \psi .
$$

Then we define the value of seeder's return $S V\left(S_{t}, H_{t}\right)$ by:

$$
S V\left(S_{t}, H_{t}\right)=\bar{\psi} F\left(S_{t}, H_{t}\right)+p_{b}(b, s) \phi S_{0},
$$

where $\bar{\psi}$ is the seed cost under the new setting. According to the equilibrium asset pricing theory, the seeder's payoff $S V\left(S_{0}, H_{0}\right)$ from the seeding deal should equal to the seed capital provided when signing the contract, i.e.,

$$
S V\left(S_{0}, H_{0}\right) \equiv \phi S_{0} .
$$

${ }^{10}$ One can find the computational details in Duffie (2001). Similar to Wang, Wang and Yang (2012) and Song, Yang and Yang (2013) among others, we denote $s$ as AUM/HWM ratio, i.e. $s=S / H$, an effective variable in our model that is given by

$$
\frac{d s_{t}}{s_{t}}=(\alpha+r-\delta-c) d t+\rho \sigma d B_{t}+\epsilon d Z_{t}, s_{t}<1 .
$$


Thus the seeding cost in this new setting, denoted by $\bar{\psi}$, is given by

$$
\begin{aligned}
\bar{\psi} & =\left(1-p_{b}\left(b, s_{0}\right)\right) \phi S_{0} / F\left(S_{0}, S_{0}\right), \\
& =\left(1-p_{b}\left(b, s_{0}\right)\right) \psi
\end{aligned}
$$

Unlike the case that seeder's value could be as low as zero in Ewald and Zhang (2016) as well as our benchmark model, here the seeder's payoff is well protected. By comparing Equation (12) and (20), we find that the seeder's payoff in the guarantee scheme faces less risk at liquidation with a guranteed paymetns of $\phi S_{0}$ instead of zero.

After submitting Equation (22) and (19) into Equation (14) we have the manager's payoff as

$$
M V\left(S_{0}, S_{0}\right)=(1-\psi) F\left(S_{0}, s_{0}\right)+\phi I\left(S_{0}, s_{0}\right) .
$$

The manager's value here with fees-for-guarantee swap is exactly the same as in Equation (9) under the benchmark model when the contract commences, which means that the manager transfers $\varphi \equiv p_{b}\left(b, s_{0}\right) \psi$ percent fees from the seeder to the insurer and pays no extras under guarantee framework.

Finally, the total present value of hedge fund $\operatorname{HFV}\left(S_{t}, H_{t}\right)$, i.e. the sum of managerial compensation, the seeder's payoff and ordinary investors' value, is given by:

$$
\begin{aligned}
H F V\left(S_{t}, H_{t}\right) & \equiv M V\left(S_{t}, H_{t}\right)+S V\left(S_{t}, H_{t}\right)+(1-\phi) I\left(S_{t}, H_{t}\right), \\
& =F\left(S_{t}, H_{t}\right)+I\left(S_{t}, H_{t}\right),
\end{aligned}
$$

which is the same as in (13). As in our model the fund performance has been exogenously determined by the alpha strategy only, the guarantee mechanism here has not contributed to the performance. Instead, it forces the ESFs manager to put aside part of her earnings to refund the seeder's initial investment once the fund defaults.

\subsection{Breakeven alpha strategy}

An extremely important question for investors is: what is the minimum $\alpha$ to be delivered by the manager to justify the carried interest $(k)$, or for ordinary investors to break even $(I(S, S)=S)$ ? Identically, how large a performance fee should be charged for a given level of performance. Using Equation (A.13) to solve $I(S, S)=S$ for $k$ gives the maximum high water performance fee justified by a particular $\alpha$ :

$$
k^{*}(\alpha)=\frac{1-\theta_{2}+\bar{\theta} b^{1-\theta_{1}}+\left(\theta_{1}-1\right) b^{\bar{\theta}}}{\theta_{2}-\theta_{1} b^{\bar{\theta}}-\bar{\theta} b^{1-\theta_{1}}-(\delta+\lambda)\left(1-b^{\bar{\theta}}\right) /(\alpha-c)} .
$$

Equation (25) is quite similar to Equation (18) in Goetzmann, Ingersoll and Ross (2003), however, they are different in terms of liquidation thresholds, as ours is $\phi$ percent lower due to the managerial ownership. Theoretically, $k^{*}$, in Equation (25), could be as low as zero or even negative. This means that the investors will not willing to enter the contract even for a positive performance $\alpha$.This is because a smaller positive $\alpha$ may only justify management fees ( $c=150$ base points here in our model) compensated to ESFs managers but not enough for both the management fees and performance fees. This is further consistent with Goetzmann, Ingersoll and Ross (2003) that "hedge funds may well charge less ... Then, managers might be earning (management) fees only just 
sufficient to draw them into the business." Other than the breakeven alpha strategy case, in practice investors either make losses or collect surplus depending on whether they hire a more skilled manager than the breakeven case or not. Therefore, it is quite essential for investors to access managers' skill correctly.

\section{Quantitative Results}

To develop more intuitive understanding of our theoretical findings, here we present numerical analyzes on the impact of HWM, managerial stake, and the possibility of fund liquidation on ESFs managers' risk shifting behaviour under the innovative scheme with the fees-for-guarantee swaps. In order to make a comparison, following Goetzmann, Ingersoll and Ross (2003), our numerical results are based on the following annualized baseline parameter values: typical parameter values $r+c^{\prime}-g=5$ percent, $k=20$ percent, $c=1.5$ percent, $\delta+\lambda=10$ percent, fund volatility $\sigma=20$ percent, alpha skills $\alpha=5$ percent, and liquidation barrier $l=0.5$, managerial stake $\phi=10$ percent thus the effective liquidation barrier $b \equiv l(1-\phi)=0.45$.

\subsection{The seeder's payoff and contract designing of fees-for-seed ratio}

\subsubsection{Seeders' return profile with and without fees-for-guarantee swap}

Here we present more insights on how fees-for-guarantee swap helps seeders control their downside risk. Seeders' payoff with both guarantee and fees-for-seed swap is much less volatile compared with the case for fees-for-seed swap only. As discussed in Section 2, seeders' return profile is guaranteed at prefixed level (usually equals to her initial investment) once fund liquidation occurs, thus the liquidation risks is well under control with guarantee.

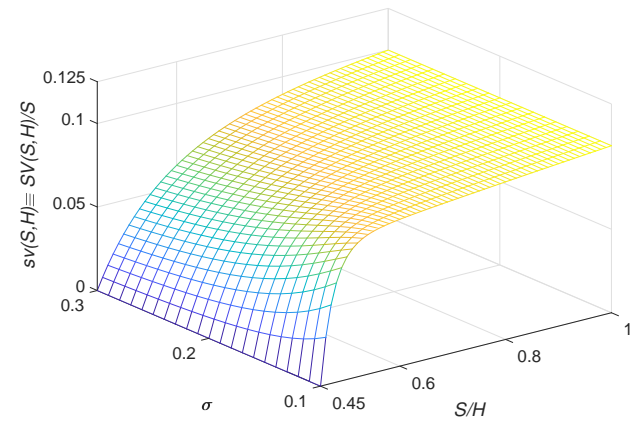

Figure 1. The impact of fund performance $S / H$, fund volatility $\sigma$ on the seeder's payoff with a liquidation barrier $l=0.5$ but without guarantee.

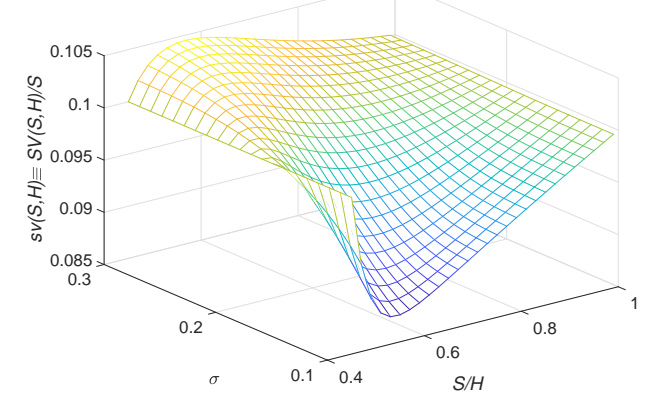

Figure 2. The impact of fund performance $S / H$, fund volatility $\sigma$ on on the seeder's payoff with a liquidation barrier $l=0.5$ with guarantee.

The seeder's value in Ewald and Zhang (2016) as well as in our benchmark model shows the great profit potential once the funds performs well, however, the seeder might loss all her investment once the fund defaults. In contract, the seeder's payoff in our framework with guarantee is well protected and redeems initial investment when the fund is liquidated. More specifically, the seeder's payoff in Figure1 without guarantee is an increasing function of fund performance but a decreasing function of fund risks. However, Figure 2 shows that seeders' return is an increasing function of fund risks 
and a more complex function of performance. More specifically, the seeder's payoff gets worse for even a better performance of the hedge fund with significantly high risk. At first glimpse it seems beyond belief, however, the reason is quite simple that extremely high level of risk outweighs the benefit from the fund's performance. Therefore, the seeder prefers a liquidation to redeem her investment than keeping investing in a fund with poor performance.

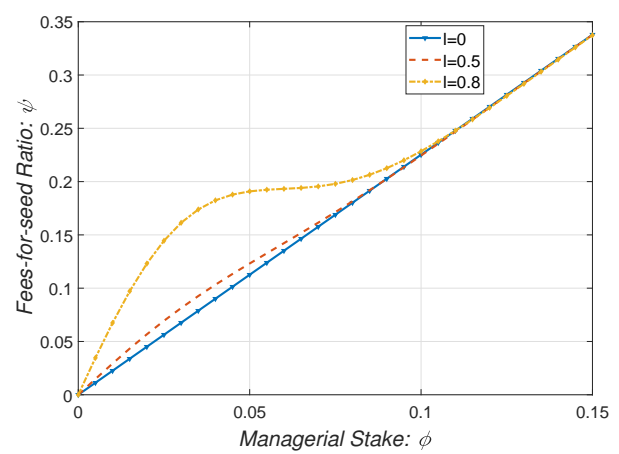

Figure 3. The impact of managerial stake $\phi$ on the initial designing of fees-for-seed swap ratio $\psi$ with three different liquidation barriers. In this case, we choose a higher volatility $(\sigma=30 \%)$ in order to highlight the liquidation effect.

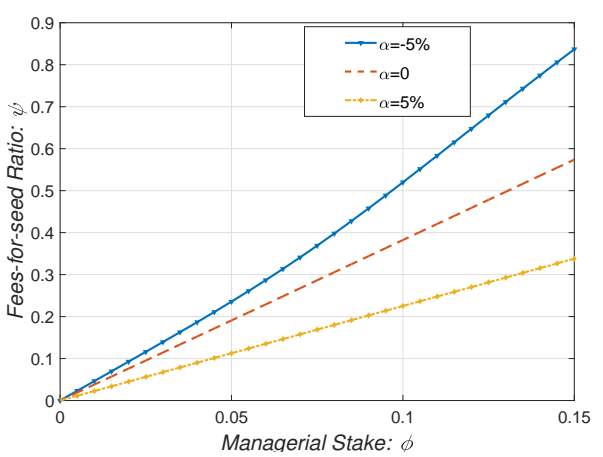

Figure 4. The impact of managerial stake $\phi$ on the initial designing of fees-for-seed swap ratio $\psi$ with three different levels of manager skills. Similar to Fig.3, fund volatility $\sigma$ is $30 \%$.

\subsubsection{Contract designing: fees-for-seed ratio}

As Goetzmann, Ingersoll and Ross (2003) states, "In particular, if investment capital is a scarce resource relative to potential hedge fund managers, virtually all benefits of the hedge funds may go to investors ". Our numerical results back up the above statements: to highlights the difference, we consider a extreme case that a manager with lower alpha skills $(\alpha=-5 \%)$ has to give up $85 \%$ fees to a seeder in exchange for $15 \%$ fund's ownership, while a much more skilled manager $(\alpha=5 \%)$ gives up only $35 \%$ of her fees, as indicated in Figure 4 . This is also consistent with Ewald and Zhang (2016) that "the seeder demands more fund revenue share ... and the difference (between good and bad performance managers) can be up to 40\%". Both Figure 3 and Figure 4 indicate that a manager has to give up a larger fraction of her performance fees to exchange a greater amount of seed capital, as expected. Interestingly, most of our numerical results from Figure 3 and Figure 4 reveal nonlinear relationships between the fees-for-seed ration and managerial stake except for ESFs managers who face no endogenous liquidation risks (i.e. $l=0$ ). The rationale is that managerial stake has nonlinear effects of $\psi$ in our model through affecting the liquidation barrier and these effects disappear once the liquidation $l$ is zero.

\subsection{The insurer's claim, i.e. guarantee costs $\varphi$}

Generally speaking, an insurer will diversify idiosyncratic risks by signing a great many of contracts with different ESFs managers with various types of invest strategies. Thus, it is reasonable to assume that insurers only bear systematic risks and the idiosyncratic risks of hedge funds will be well-diversified. Figure 5 shows the guarantee costs boosts, as expected, as the increase of fund risks. Moreover, the better performance the fund 
delivers, the smaller guarantee cost the manager faces. These observations are consistent with economic intuition since a manager with better skills generates more fees and profits. More specifically, as the fund risk increases from $10 \%$ to $30 \%$, the guarantee costs rises up slowly form naught to $5 \%$ for a better performance of $\alpha=5 \%$, while it rises dramatically from $4 \%$ to $26 \%$ for a poor performance of $\alpha=-5 \%$.

In addition, we present illusive results of the effect of liquidation barrier on guarantee costs. Figure 6 shows that given a higher level of fund risk, such as $30 \%$, the guarantee costs for a higher liquidation barrier ESFs fund at $l=0.8 \%$ is around 45 percent. By contrast, the ESFs fund with a lower barrier at $l=0.5 \%$ costs only 5 percent of fees. This is obvious as a higher liquidation barrier indicates greater liquidation risks, thus larger guarantee costs demanded by the insurer. Interestingly, as the ESFs fund volatility decreases, this gap becomes smaller, and finally disappears. If there is no liquidation barrier, then no guarantee scheme would be necessary as the fund has no liquidation risks, which is a case against reality.

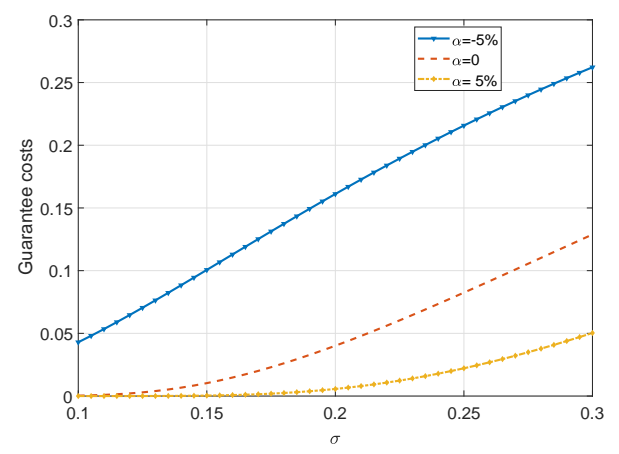

Figure 5. The impact of fund risk $\sigma$ on the value of guarantee costs $\varphi$ with three different values of alpha skills.

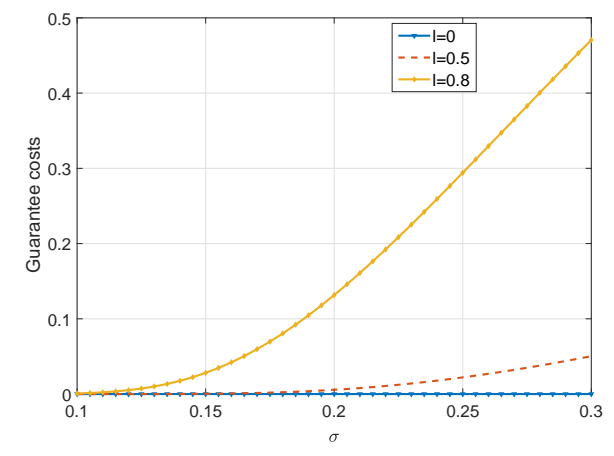

Figure 6. The impact of fund risk $\sigma$ on the value of guarantee costs $\varphi$ with three different values of liquidation barrier.

\subsection{Risk shifting behaviour of ESFs managers at the stage hedge fund seeding}

\subsubsection{The effect of liquidation barrier}

Similar to Carpenter (2000), it is optimal for ESFs managers who is compensated through an asymmetric bonus fee and faces no explicit downside risks to take extreme risks when she is further away from the money.

The risk shifting behaviour for ESFs managers has been illustrated in Figure 7: as the total compensation value of the ESFs manager is always an increasing function of fund volatility, which means the ESFs manager has great incentive to shift risk. By contrast, risk shifting behaviour has been largely cubed once the ESFs manager faces explicit downside risk, as is shown in Figure 8. This result is generally consistent with Hodder and Jackwerth (2007), Basak, Pavlova, and Shapiro (2007) and Aragon and Nanda (2012). Given the existence of downside liquidation risks, ESFs managers face tradeoff between the potential gain from the performance fees and loss from management fees and her fund ownership as well when shifting risks. For a ESFs manager with a higher liquidation barrier, the negative effect from losses of management fees and her ownership outweighs the risk shifting benefits from beating the HWM (or performance fees), thus risk shifting behaviour is a suboptimal strategy as it leads to 


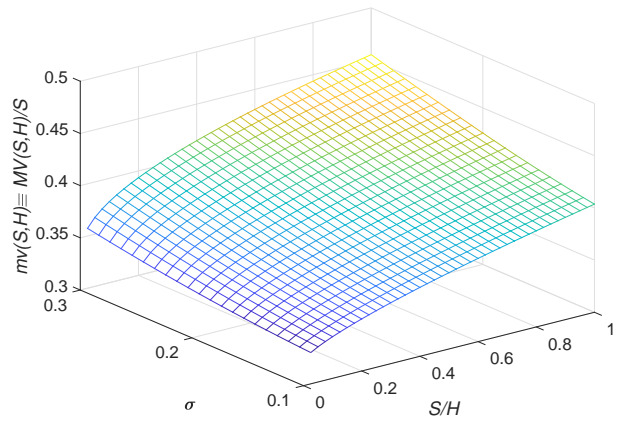

Figure 7. The impact of fund performance $S / H$, fund volatility $\sigma$ on the value of the ESFs manager's total compensation when the manager faces no downside risk, i.e. liquidation barrier $l=0$.

less compensation for the ESFs manager.

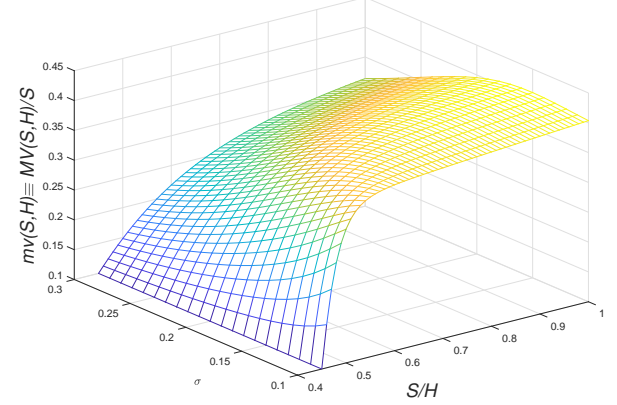

Figure 9. The impact of fund performance $S / H$, fund volatility $\sigma$ on the value of the ESFs manager's total compensation. In this case the manager's ownership is $\phi=10 \%$.

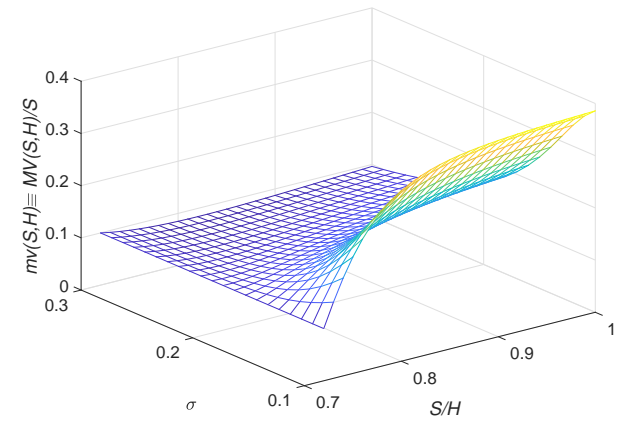

Figure 8. The impact of fund performance $S / H$, fund volatility $\sigma$ on the value of the ESFs manager's total compensation. In this case the liquidation barrier $l=0.8$.

Our model suggests that optimal contract designing not only moderates risk shifting following poor performance, but also encourages profit chasing. As is illustrated in Figure 9, the manager will choose lower volatility in order to dramatically reduce the chance of hitting the liquidation boundary. However, increasing risk slightly could be optimal once the AUM is near its HWM. The intuition is quite simple: the manager will take gambles to collect the huge profits once AUM reaches the HWM.

\subsubsection{The effect of managerial stakes}

Generally speaking, an ESFs manager will not take great gambles following poor fund performance when having their own investment in the fund (See e.g. Carpenter (2000), Basak, Pavlova, and Shapiro (2007), Hodder and Jackwerth (2007) and Aragon and Nanda (2012) among others.). Our numerical results show that the managerial stake is effective in moderating the ESFs manager's incentive to shift risk when the fund is likely to liquidate endogenously.

As Figure 10 shows: when the current AUM is near the liquidation barrier $(x \rightarrow$ 0.5), ESFs managers without fund ownership experience a relatively small increase of total compensation value of $6.5 \%$ (from around $3.5 \%$ to 10\%) if she reduces the fund 
volatility from $30 \%$ to $10 \%$. On the contrary, the ESFs manager's total compensation value increases $18 \%$ (from around $15.7 \%$ to $33.9 \%$ ). The illusive results show that the manager who has her own investment in the fund in will largely improve her welfare when AUM near the initial liquidation barrier $(l=0.5)$ by decreasing the fund volatility dramatically, thus mitigating the manager's risk shifting behaviour.

\subsection{The breakeven $\alpha$ strategy}

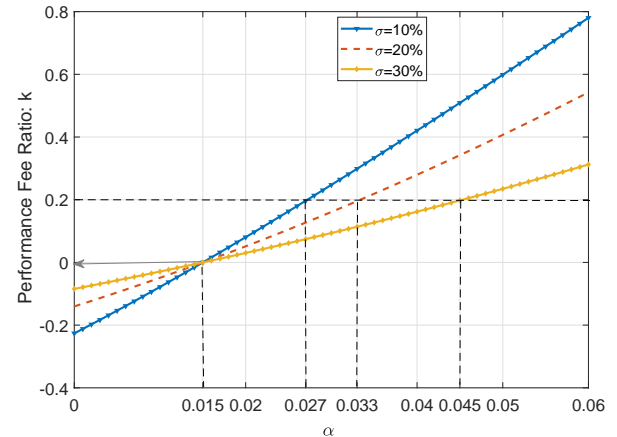

Figure 11. The maximum performance fee $k$ rate for different managerial skills $\alpha$ with three levels of fund volatility.

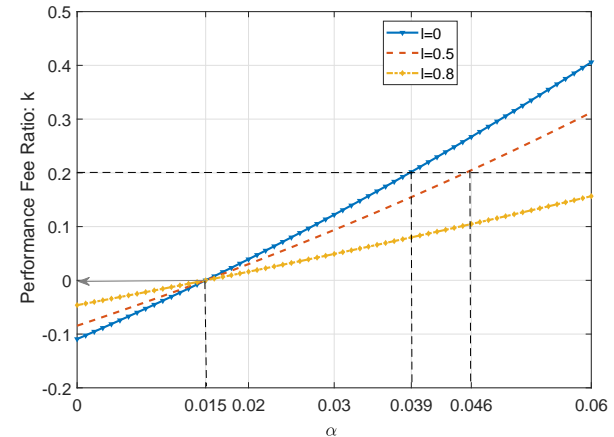

Figure 12. The sensitivity of the maximum performance fee $k$ rate for different managerial skills $\alpha$ with three different levels of liquidation barrier.

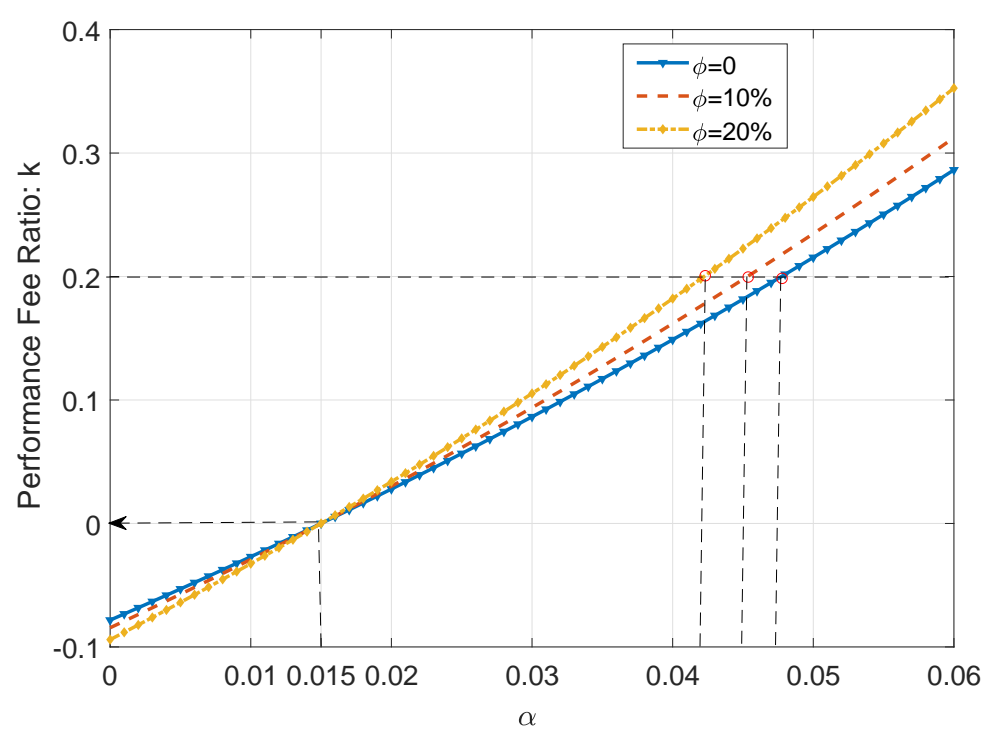

Figure 13. The sensitivity of the maximum performance fee $k$ rate for different managerial skills $\alpha$ with three different levels of seeding investment.

Finally, we provide numerical evidence showing why $\alpha$ is important both for managers and investors. As we can see from both Figure 11 and Figure 12, ESFs managers should deliver better fund performance to justify a higher performance fee, which is consistent with Goetzmann, Ingersoll and Ross (2003). More specifically, Figure 11 indicates that the minimum $\alpha$ required for three different volatility $(\sigma=10 \%, 20 \%$ and $30 \%$ ) to justify a performance fee rate (e.g. the most usual case i.e. $k=20 \%$ ) is 
270 and 330 and 450 basis points respectively. Now we turn to the effects of exogenous liquidation barrier on the maximal performance fee rate justified. Given $k=20 \%$, the excess return $(\alpha)$ demanded is 390 and 450 basis points respectively for two different liquidation barrier $(l=0,0.5)$. The intuition is simple, a lower liquidation barrier contributes to higher values for investors, thus a smaller alpha is required. Interestingly, our numerical results reveal that charging a positive performance fee is never justified for an ESFs manager who generates a $\alpha$ less than 150 basis points regardless of different level of fund risks and liquidation barriers. As hedge funds commonly charge both management fees and performance fees, poor performed funds ( $\alpha \leq 150$ base points) may only sufficient to cover management fees but the performance fees.

Figure 13 presents the effects of managerial ownerships on breakeven alphas. In general, the breakeven alpla requested by investors decreases as managerial ownership increases, other things equal. For instance, for a given fees structure $(c=1.5 \% \& K=$ $20 \%$ ) the breakeven alpha drops from $4.75 \%$ to $4.2 \%$ as the ESFs manager increases her fund ownership from zero to $20 \%$. This results are in agreeable with Ewald and Zhang (2016)'s findings that " ordinary investors are more willing to invest in an ESFs backed up by seeders via fees-for-seed swap". However, the mechanisms under are quite different: Ewald and Zhang (2016) argue that ordinary investors get incentives and benefit from their senior positions at the "waterfall" structure, while here in our framework interests between ordinary investors and the ESFs manager are well aligned as managers have skin in the game.

\section{Conclusion}

This paper studies the pricing of seeding and guarantee costs as well as analyzes the risk shifting behaviour of an ESFs manager under Black-Scholes framework. Innovative contracts, here we refer as fees-for-guarantee swap and fees-for-seed swap, have been introduced in this paper to improve managers credibility resulting from severe information asymmetry between seeders and ESFs managers. The main conclusions are detailed explicitly while some numerical examples are provided for illustrations as well.

We find that seeders in our innovative scheme bear less risks than those in practice who only sign fees-for-seed swaps at the seeding stage. This intuition is straightforward as the seeder in our setting still redeems her initial investment from the insurer at the fund liquidation point. These innovative swaps also ensure that interests among seeders, insurers, and ESFs managers are effectively aligned.

Closed-form solution of fees-for-seed ratio has been derived in our model instead of a rule of thumb in reality. We also provide detailed numerical analysis for more insights. The larger the amount of seed capital obtained, the more fees ESFs managers have to give up, as we expect. Interestingly, most of our quantitative results (except the case of no liquidation risks) reveal a nonlinear relationship between the fees-for-seed ratio and managerial stake, which is quite different from the "thumb rule" in practice. Our findings show that when AUM is close to its liquidation barrier, the guarantee costs rises as the increase of fund risks. As a higher level of fund volatility leads to a greater probability of compensatory payment to be paid by an insurer, by whom thus a greater guarantee costs is demanded.

Interestingly, our numerical findings reveal that charging a positive performance fee is never justified for an ESFs manager who has poor fund performances with an $\alpha$ less than 150 basis points regardless of the fund risk levels and liquidation barriers. 
Other than the breakeven alpha strategy case, it is not uncommon that investors either make losses or collect surplus depending on whether they hire a more skilled manager than the breakeven case or not. Therefore, it is quite essential for investors to access managers' skill correctly.

Finally, our model suggests that optimal contract designing, i.e. the determination of swap ratios e.g. $\psi$ and $\varphi$ could not only moderate risk shifting following poor performance, but also give managers incentive to chasing profits. For example, numerical results show that managerial stake is an effective tool in terms of moderating the ESFs manager's incentive to shift risk when her fund bears liquidation risks.

Several opportunities exist for future research. On the one hand, dynamic leverage can be incorporated into our model to further analyse ESFs managers' risk shifting behaviour, inspired by Lan, Wang and Yang (2013). On the other hand, we can extend our model to capture the risk-averse magnitude of both ESFs managers and investors, see Sorensen, Wang and Yang (2014), Wang, Wang and Yang (2012) among others. Motivated by recent portfolio insurance literature, see Cont and Tankov (2009) and Zieling et al. (2014) for example, it would also be interesting to analyse the most effective PI approaches the insurer could adopt to hedge the risks embedded in the hedge fund seeding business.

\section{Acknowledgement(s)}

We are grateful for helpful discussions with and comments from Chris Adcock (Editor), two anonymous referees, Dimitris Andriosopoulos, Daniel Broby, John Crosby, Christian Ewald, Jinqiang Yang and Zhaojun Yang, and participants on The Fourth Chinese Capital Markets Conference (2014).

\section{Funding}

The research for this paper was supported by National Natural Science Foundation of China (Project Nos. 71371068)

\section{References}

Agarwal, V., N.D. Daniel, and N.Y. Naik. 2009. Role of managerial incentives and discretion in hedge fund performance. Journal of Finance, 64, 2221-2256.

Agarwal, V., N.D. Daniel, and N.Y. Naik. 2011. Do hedge funds manage their reported returns? Review of Financial Studies, 24, 3281-3320.

Aggarwal, R.K., and P. Jorion. 2010. The performance of emerging hedge funds and managers. Journal of Financial Economics, 96, 238-256.

Aiken, A.L., C.P. Clifford, and J. Ellis. 2013. Out of the dark: hedge fund reporting biases and commercial databases. Review of Financial Studies, 26, 208-243.

Aragon, G.O., and V. Nanda. 2012. Tournament behavior in hedge funds: high-water marks, fund liquidation, and managerial stake. Review of Financial Studies, 25, 937-974.

Basak, S., 2002. A comparative study of portfolio insurance. Journal of Economic Dynamics and Control 26 (7-8), 12171241.

Basak, S., A. Pavlova, and A. Shapiro. 2007. Optimal Asset Allocation and Risk Shifting in Money Management. Review of Financial Studies, 20, 1583-621. 
Black, F., Jones, R., 1987. Simplifying portfolio insurance. Journal of Portfolio Management $13,4851$.

Carpenter, J. 2000. Does option compensation increase managerial risk appetite? Journal of Finance, 15, 2311-2331.

Cont, R., P., Tankov, 2009. Constant proportion portfolio insurance in the presence of jumps in asset prices. Mathematical Finance 19, 379401.

Duffie, D. 2001. Dynamic asset pricing theory, 3rd ed. Princeton, NJ: University Press.

Ewald, C., H. Zhang, 2016. Hedge fund seeding via fees-for-seed swaps udner idiosyncratic risk. Journal of Economic Dynamics and Control, 71, 45-59.

Fung, W., D. Hsieh, 1997. Empirical characteristics of dynamic trading strategies: the case of hedge funds. Review of Financial Studies, 10, 275-302.

Fung, W., and D. Hsieh, 1999. A Primer on Hedge Funds. Journal of Empirical Finance, 6, 309-331.

Goetzmann, W.N., J. Ingersoll, and S.A. Ross. 2003. High-water marks and hedge fund management contracts. Journal of Finance, 58, 1685-1717.

Grossman, S.J., and Z. Zhou. 1993. Optimal investment strategies for controlling drawdowns. Mathematical Finance, 3, 241-276.

Hodder, J.E., and J.C.Jackwerth. 2007. Incentive contracts and hedge fund management. Journal of Financial and Quantitative Analysis, 42, 811-826.

Ingersoll, J.E. 2006. The subjective and objective evaluation of incentive stock options. Journal of Business, 79, 453-487.

Lan, Y.C, N. Wang, and J.Q. Yang. 2013. The economics of hedge funds. Journal of Financial Economics, 110, 300-323.

Ho, L.C., J. Cadle, M. Theobald, 2010. Portfolio Insurance Strategies: Review of Theory and Empirical Studies. In: CF, Lee et al. (Eds.), Handbook of Quantitative Finance and Risk Management. Springer, Berlin.

Leland, H.E., M. Rubinstein, 1976. The evolution of portfolio insurance. In: Luskin, D.L. (Ed.), Portfolio Insurance: A Guide to Dynamic Hedging. Wiley, Hoboken, New Jersey.

Merton, R.C. 1976. Option pricing when underlying stock returns are discontinuous. Journal of Financial Economics, 3(1-2), 125-144.

Panageas, S., and M.M. Westerfield. 2009. High-water marks: high risk appetite? Convex compensation, long horizons, and portfolio choice. Journal of Finance, 64, 1-36.

Ross, S.A. 2004. Compensation, incentives, and the duality of risk aversion and riskiness. Journal of Finance, 59, 207-225.

Song, D., J.Q. Yang, and Z.J. Yang. 2013. High-water marks and hedge fund management contracts with partial Information. Computational Economics, 42(3), 327-350.

Sorensen, M., N. Wang, and J.Q. Yang. 2014. Value private equity. Review of Financial Studies, 27(7), 1977-2021.

Stiglitz, J. E., and Weiss, A. 1981. Credit rationing in markets with imperfect information. American Economic Review, 71(3), 393-410.

Tang, X.L., and Yang, Z.J. 2017. Optimal Investment and Financing with Macroeconomic Risk and Loan Guarantees, Journal of Credit Risk, forthcoming.

Wang, C., N. Wang, and J.Q. Yang. 2012. A unified model of entrepreneurship dynamics. Journal of Financial Economics, 106, 1-23.

Yang, Z.J., and H. Zhang. 2013. Optimal capital structure with an equity-for-guarantee swap. Economics Letters, 118(2), 355-359.

Zieling, D., A. Mahayni, S. Balder, 2014. Performance evaluation of optimized portfolio insurance strategies. Journal of Banking and Finance, 43, 212-225. 


\section{Appendix A. Pricing a hedge fund}

In this appendix, we provide details of computing equilibrium values of contingent claims associated with a hedge fund.

In order to derive the equilibrium value of fees and investor claim (Equations (5) to (7)) defined in Section (2.1), two boundary conditions are required. The first one indicates that once the asset value falls to the liquidation level, $\underline{S}\left(H_{t}\right)$, then investors will withdraw all his money from the hedge fund and there are no further costs or fees generated.

$$
A\left(\underline{S}\left(H_{t}\right), H_{t}\right)=0, P\left(\underline{S}\left(H_{t}\right), H_{t}\right)=0, I\left(\underline{S}\left(H_{t}\right), H_{t}\right)=\underline{S}\left(H_{t}\right),
$$

where $\underline{S}\left(H_{t}\right)=l H_{t}$.

The other one applies along with the boundary $S_{t}=H_{t}$. The HWM is reset to $H_{t}+\varepsilon$, while the net asset value excess the HWM to $H_{t}+\varepsilon$ and then the manager obtain a performance fee of $k \varepsilon$, reducing the asset value to $H_{t}+\varepsilon(1-k)$. So, we have

$$
P\left(H_{t}+\varepsilon, H_{t}\right)-P\left(H_{t}+\varepsilon-k \varepsilon, H_{t}\right)=k \varepsilon,
$$

In the limit, as $\varepsilon \rightarrow 0$, and using Taylor's expansion rule, giving the second boundary condition

$$
k P_{S}\left(H_{t}, H_{t}\right)=k+P_{H}\left(H_{t}, H_{t}\right)
$$

and boundary conditions for the management fees and the investor's claim are given by

$$
k A_{S}\left(H_{t}, H_{t}\right)=A_{H}\left(H_{t}, H_{t}\right), k I_{S}\left(H_{t}, H_{t}\right)=I_{H}\left(H_{t}, H_{t}\right) .
$$

According to the dynamic asset pricing theory (Duffie (2001)), one can derive the following equilibrium price

$$
V^{f}\left(S_{t}, H_{t}\right)=\mathbb{E}^{\mathbb{Q}}\left[\int_{t}^{\tau} \exp (-r(s-t)) f\left(y_{s}\right) d s \mid S_{t}=S_{0}, H_{t}=H_{0}\right],
$$

for any contingent claim underlying $\operatorname{AUM}\left(S_{t}\right)$ and $\operatorname{HWM}\left(H_{t}\right)$ with a payment flow $f\left(S_{t}, H_{t}\right)$ to the claimant. If $f(\cdot)$ is a linear function, $V^{f}(y)$ can be determined by solving the integral directly. Similar to Goetzmann, Ingersoll and Ross (2003), the value function is time independent, i.e. $V_{t}^{f}=0$. Thus, the function $V^{f}(y)$ satisfies the following ODE from Ito's formula

$$
(\alpha+r-\delta-c) S V_{S}^{f}+\frac{1}{2} \sigma^{2} S^{2} V_{S S}^{f}+\left(g-\delta-c^{\prime}\right) H V_{H}^{f}+\lambda\left(f(M)-V^{f}\right)-r V^{f}=0 .
$$

One can identify the solution of function $V^{f}\left(S_{t}, H_{t}\right)$ by specifying the general solution of the homogeneous ODE with boundary conditions defined in Equations (A.1), (A.3) and (A.4).

Further, it is clear by the economics of the problem that $V^{f}$ is homogeneous of degree one in $S$ and $H$, so the solution has the form $V^{f}\left(S_{t}, H_{t}\right)=H_{t} G(s)$. Substituting this 
and its derivatives into Equation (A.6) gives an ODE

$$
\frac{1}{2} \sigma^{2} x^{2} G_{s s}+\left(\alpha+r+c^{\prime}-g-c\right) s G_{s}-\left(r+c^{\prime}-g+\delta+\lambda\right) G+\gamma s=0,
$$

where $\gamma=0$ for $f=P, \gamma=c$ for $f=A$ or $f=F$, and $\gamma=\delta+\lambda$ for $f=I$.

The solution to Equation (A.7) is given by

$$
G(s)=\frac{\gamma s}{c+\delta+\lambda-\alpha}+A s^{\theta_{1}}+B s^{\theta_{2}},
$$

where $\mathrm{A}$ and $\mathrm{B}$ are constants of integration and the two real roots, denoted by $\theta_{1}$ and $\theta_{2}$ solve the following quadratic equation:

$$
\frac{1}{2} \sigma^{2} \theta(\theta-1)+\left(\alpha+r+c^{\prime}-c-g\right) \theta-\left(r+c^{\prime}-g+\delta+\lambda\right)=0 .
$$

Solving the above equation and with the no bubble conditions $c+\delta+\lambda \geq \alpha$ easily gives

$$
\theta_{1,2}=\frac{-\left(\varpi-\sigma^{2} / 2\right) \mp \sqrt{\left(\varpi-\sigma^{2} / 2\right)^{2}+2 \sigma^{2}(\varpi+m-\alpha+\delta+\lambda)}}{\sigma^{2}},
$$

where $\varpi \equiv \alpha+r+c^{\prime}-m-g$ obviously $\theta_{1}<1<\theta_{2}$.

Therefore the equilibrium value of the total fees, performance fee and the investor's claim are

$$
\begin{aligned}
& F\left(S_{t}, H_{t}\right)=\frac{c}{c+\delta+\lambda-\alpha} S_{t}+\frac{(\delta+\lambda-\alpha) k+\left[\theta_{1}(1+k)-1\right] c l^{1-\theta_{1}}}{(c+\delta+\lambda-\alpha)\left\{\theta_{2}(1+k)-1-l^{\theta_{2}-\theta_{1}}\left[\theta_{1}(1+k)-1\right]\right\}} H_{t}^{1-\theta_{2}} S_{t}{ }^{\theta_{2}} \\
& -\frac{l^{\theta_{2}-\theta_{1}}(\delta+\lambda-\alpha) k+\left[\theta_{2}(1+k)-1\right] c l^{1-\theta_{1}}}{(c+\delta+\lambda-\alpha)\left\{\theta_{2}(1+k)-1-l^{\theta_{2}-\theta_{1}}\left[\theta_{1}(1+k)-1\right]\right\}} H_{t}{ }^{1-\theta_{1}} S_{t}{ }^{\theta_{1}} \text {, } \\
& P\left(S_{t}, H_{t}\right)=k \frac{H_{t}{ }^{1-\theta_{2}} S_{t}^{\theta_{2}}-l^{\theta_{2}-\theta_{1}} H_{t}{ }^{1-\theta_{1}} S_{t}^{\theta_{1}}}{\theta_{2}(1+k)-1-l^{\theta_{2}-\theta_{1}}\left[\theta_{1}(1+k)-1\right]}, \\
& \begin{aligned}
I\left(S_{t}, H_{t}\right) & =\frac{\delta+\lambda}{c+\delta+\lambda-\alpha} S_{t}-\frac{(\delta+\lambda) k+\left[\theta_{1}(1+k)-1\right](c-\alpha) l^{1-\theta_{1}}}{(c+\delta+\lambda-\alpha)\left\{\theta_{2}(1+k)-1-l^{\theta_{2}-\theta_{1}}\left[\theta_{1}(1+k)-1\right]\right\}} H_{t}{ }^{1-\theta_{2}} S_{t}{ }^{\theta_{2}} \\
& +\frac{l^{\theta_{2}-\theta_{1}}(\delta+\lambda) k+\left[\theta_{2}(1+k)-1\right](c-\alpha) l^{1-\theta_{1}}}{(c+\delta+\lambda-\alpha)\left\{\theta_{2}(1+k)-1-l^{\theta_{2}-\theta_{1}}\left[\theta_{1}(1+k)-1\right]\right\}} H_{t}{ }^{1-\theta_{1}} S_{t}^{\theta_{1}} .
\end{aligned}
\end{aligned}
$$

Thus the management fees $A\left(S_{t}, H_{t}\right)$ is given by

$$
A\left(S_{t}, H_{t}\right)=F\left(S_{t}, H_{t}\right)-P\left(S_{t}, H_{t}\right) .
$$

